\title{
Acclimation of cuttings from different willow genotypes to flooding depth level
}

\section{María E. Rodríguez, Guillermo N. Doffo, Teresa Cerrillo \& Virginia M. C. Luquez}

\section{New Forests}

International Journal on the Biology, Biotechnology, and Management of Afforestation and Reforestation

ISSN 0169-4286

Volume 49

Number 3

New Forests (2018) 49:415-427

DOI 10.1007/s11056-018-9627-7

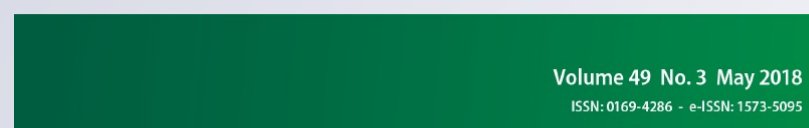

an international journal

New Forests

biology, biotechnology, and management of afforestation and reforestation

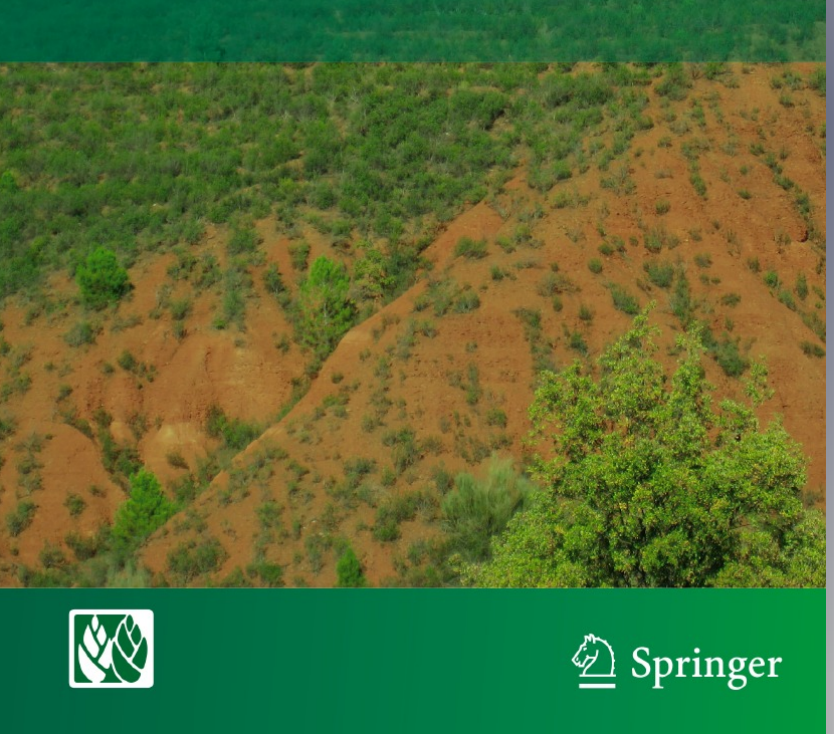


Your article is protected by copyright and all rights are held exclusively by Springer Science+Business Media B.V., part of Springer Nature. This e-offprint is for personal use only and shall not be self-archived in electronic repositories. If you wish to self-archive your article, please use the accepted manuscript version for posting on your own website. You may further deposit the accepted manuscript version in any repository, provided it is only made publicly available 12 months after official publication or later and provided acknowledgement is given to the original source of publication and a link is inserted to the published article on Springer's website. The link must be accompanied by the following text: "The final publication is available at link.springer.com". 


\title{
Acclimation of cuttings from different willow genotypes to flooding depth level
}

\author{
María E. Rodríguez ${ }^{1}$ - Guillermo N. Doffo ${ }^{1} \cdot$ Teresa Cerrillo $^{2} \cdot$ Virginia M. C. Luquez $^{1}$
}

Received: 12 June 2017 / Accepted: 17 January 2018 / Published online: 20 January 2018

(C) Springer Science+Business Media B.V., part of Springer Nature 2018

\begin{abstract}
Climate change will increase the frequency of extreme rain events, causing more flooding episodes. Willows are usually planted in marginal lands like flood prone areas. For willow plantations developed from rootless cuttings, the establishment phase is crucial, because the cuttings are still developing a shoot and root system and have a higher vulnerability to stress. A flooding episode during this early period may have a negative effect upon plants. We analyzed the responses to flooding of eight willow genotypes, representing important species from the economic and ecological point of view (Salix alba, $S$. matsudana, S. amygdaloides and $S$. matsudana $\times S$. nigra hybrids). The treatments started when the plants were 2 months old and lasted for 3 weeks. They were identified as: Control (watered to field capacity); F10 (plants submerged $10 \mathrm{~cm}$ above soil surface) and F50 (plants submerged $50 \mathrm{~cm}$ above soil surface). The F50 treatment showed a greater growth reduction than the F10 treatment in most clones, either measured in height, diameter or total biomass. Both flooding treatments reduced significantly the root-to-shoot ratio compared to control plants. The F50 treatment increased the leaf nitrogen content and specific leaf area in all genotypes. Both treatments changed plant and leaf traits in different ways according to the depth of the floodwater. These changes may have lasting effects on growth recovery in the post-flooding period. Willow clones with a fast initial growth will be the best option to minimize growth reduction in areas prone to experience flooding episodes.
\end{abstract}

Keywords Flooding $\cdot$ Nitrogen $\cdot$ Specific leaf area $\cdot$ Root-to-shoot ratio $\cdot$ Salix spp.

Electronic supplementary material The online version of this article (https://doi.org/10.1007/s110 56-018-9627-7) contains supplementary material, which is available to authorized users.

Virginia M. C. Luquez

vluquez@agro.unlp.edu.ar

1 Instituto de Fisiología Vegetal (INFIVE), UNLP - CONICET, FCAyF, CC 327, 1900 La Plata, Argentina

2 INTA Delta, Río Paraná de Las Palmas y Canal Laurentino Comas, 2804 Campana, Argentina 


\section{Introduction}

Willows (Salix spp.) are important forest trees, with different uses at industrial level (pulp, paper, reconstituted wood panels); biomass for energy (Balatinecz et al. 2014) and for environmental restoration projects (Wang et al. 2017). From 1990 to 2010, the global market of wood based products increased, and this trend is expected to continue in the future. Willows can fulfill these demands because of their fast growth rate, and in consequence their area plantation has been increasing in the last years at global level (Ma and Lebedys 2014). These plantations can be established in marginal areas not used for agriculture, like flood-prone lowland areas, where flood- tolerant willows can be grown (Dickmann and Kuzovkina 2014). Willows form natural stands in periodically flood-disturbed environments (Karrenberg et al. 2002; Markus-Michalczyk et al. 2016), and the regeneration of willow dominated riparian forests is characterized by the periodic massive germination of seeds along river banks (Van Splunder et al. 1995). Floodwater level and seed dispersal timing are the main determinants for willow seedlings survival (Blom 1999). In contrast with natural forests, commercial clonal willow plantations are mostly developed from cuttings, not seedlings. The standard propagation material for willows is un-rooted dormant cuttings, harvested from 1 year old shoots, and the establishment phase is a crucial point (Volk et al. 2004). At this stage, the vulnerability to stress is higher because the cuttings are still developing a root system and the leaf area that will provide photosynthates for subsequent growth. Accordingly, a flooding episode during the establishment period may have a negative effect upon the survival and early growth of plants (Stanturf and Van Oosten 2014). Climate change will increase the frequency of floods in several areas across the world, not only in areas near water courses but also in lowland areas, due to extreme rainfall events (Voesenek and Bailey-Serres 2015; Garssen et al. 2015). It is important to understand the responses of willow cuttings under this stressful situation in order to breed willow clones that can survive these conditions, and mitigate the impact of climate change upon the establishment of willow plantations.

Several morphological and physiological traits that have an effect on growth and productivity can be altered by flooding, like dry matter partitioning, photosynthetic activity and leaf area (Kreuzwieser and Rennenberg 2014). It has been well-documented that plant responses to flooding are different according to the depth of floodwater (Iwanaga and Yamamoto 2008). In willows, the root-to-shoot ratio of the root system was reduced by partial flooding (Li et al. 2005; Doffo et al. 2017) and it decreased along with the depth of floodwater in an experiment simulating increased levels of tidal flooding (Markus-Michalczyk et al. 2016).

There are two patterns of response according to the depth of floodwater and the duration of the flooding episode: the Low Oxygen Quiescence Strategy (LOQS) and the Low Oxygen Escape Strategy (LOES, Voesenek and Bailey-Serres 2015). The LOQS strategy implies a reduced metabolism and growth to save energy and resources, and it is associated with species that endure prolonged complete submergence. The LOES response increases the growth of aerial organs, spending energy to grow and avoid the complete submergence of the plant, and enhancing the ventilation of submerged organs. These responses are extreme, and intermediate patterns may occur.

Plants which are tolerant to complete submergence are able to acclimate by developing different traits, such as performing underwater photosynthesis (Colmer and Pedersen 2007) or producing new leaves with a higher specific leaf area (SLA, Mommer and Visser 2005). SLA is an important trait which affects growth and productivity, and is the main 
determinant for inter-specific variation in the relative growth rate (Poorter and Evans 1998). Growth ultimately relies on photosynthetic carbon fixation, and there is a positive correlation between the photosynthetic rate and the leaf nitrogen content (Poorter and Evans 1998). In poplar, nitrogen availability modulated traits that affects whole plant carbon fixation, like saturated net photosynthesis and leaf area (Cooke et al. 2005). It has been proposed that an increase in leaf nitrogen per area basis is an acclimation to optimize nitrogen economy in willows under drought stress (Weih et al. 2011). It is not known if something similar occurs under flooding stress.

In this work, we analyzed the responses of different willow species to two depths of floodwater. These species have different origins, and are important from the economic and ecological viewpoint. Salix alba and S. matsudana are riparian, living in periodically flooded environments, while $S$. nigra and $S$. amygdaloides grow in wetlands and can tolerate long periods of flooding by stagnant water (Dickmann and Kuzovkina 2014). Because of these ecological differences, we expected to find a range of flooding tolerance in the clones used in this work, with the wetland species being more flood tolerant than the riparian.

The aim of this work is to compare the acclimation response of cuttings of eight willow genotypes to different flooding depths. The hypothesis is that willow genotypes will acclimate to the depths of floodwater in different ways, by modifying their growth, dry matter partitioning and leaf functional traits.

\section{Materials and methods}

The details of the willow species and hybrids used in this work are given in Table 1. Most of these genotypes were used as parents in breeding programs developed by the National Institute of Agriculture and Livestock Technology (INTA, Instituto Nacional de Tecnología Agropecuaria, Argentina, Cerrillo et al. 2016).

The 25-cm-long cuttings were planted in $3.5 \mathrm{~L}$ pots, filled with a 50:50 mixture of a clay soil and sand, on August 28th, 2014. One cutting per pot was planted, with five replicates for each genotype and treatment, with a total of 120 plants. The pots were placed outdoors in a garden at INFIVE, La Plata, Argentina (34 59'09"S; 57 $\left.59^{\prime} 42^{\prime \prime} \mathrm{W}\right)$, with the natural climatic conditions of late winter and early spring. The temperature and precipitation data

Table 1 List of the eight willow genotypes used in this work

\begin{tabular}{llll}
\hline Genotype & Abbreviation & Species & Observations \\
\hline Salix alba "SI58-004" & SA58 & SA & Male clone \\
Salix alba "S7" & SA7 & SA & Male clone \\
Salix alba "SI64-004" & SA64 & SA & Female clone \\
S. matsudana $\times$ S. nigra"08.09.38", & MN38 & M $\times$ N & Unknown \\
S. matsudana $\times$ S. nigra "08.09.22"a & MN22 & M $\times$ N & Unknown \\
Salix matsudana "NZ693" & M693 & SM & Female clone \\
Salix matsudana "NZ692" & M692 & SM & Female clone \\
Salix amygdaloides "CAN690" & SAM & SAM & Female clone \\
\hline
\end{tabular}

${ }^{\text {a }}$ These two clones are the open pollinated progeny of a Salix matsudana $\times$ Salix nigra mother 
were recorded by an automated meteorological station belonging to Facultad de Ciencias Astonómicas y Geofísicas, UNLP (http://meteo.fcaglp.unlp.edu.ar/, Suppl. Table 1).

In most clones, sprouting occurred between 14 and 17 days after planting. Clones Salix amygdaloides "CAN690" (SAM) and Salix alba "SI58-004" (SA58) sprouted 1 week later than the others, but this delay did not have a negative effect on the final growth. The pots were watered daily to field capacity until the beginning of the flooding treatments. Before starting the treatment, each pot was fertilized with $50 \mathrm{ml}$ of complete Hoagland solution, and the plants were pruned to one shoot per plant. The experiment started on October $23^{\text {rd }}$, 2014 and lasted for 3 weeks. The treatments were: Control (watered normally); F10 (submerged in water, $10 \mathrm{~cm}$ above soil surface, only the root system was submerged); and F50 (submerged in water, $50 \mathrm{~cm}$ above soil surface, the shoot being completely or partially submerged). The plants of the F10 treatment were flooded by placing them inside a bigger sealed pot, as previously described (Cerrillo et al. 2013). The plants in the F50 treatment were placed in a pool filled with water, and some were completely submerged but others were not, depending on their initial height. The depth of submergence was recorded as the distance between the plant apical meristem and the surface of the water. Regarding clones Salix alba "S7" (SA7) and S. matsudana $\times$ S. nigra"08.09.38" (MN38), all individuals were totally submerged, while clones S. alba "SI64-004" (SA64), SA58, S. matsudana "NZ693" (M693), S. matsudana "NZ692" (M692) and SAM emerged above water surface. For clone $S$. matsudana $\times S$. nigra "08.09.22" (MN22), some plants emerged and others were submerged. The water level in the pool was checked every day and maintained at a constant level by replacing the evaporated water when necessary.

Height, diameter, number of leaves and chlorophyll content were measured at the beginning and the end of the experiment. Stem height was measured with a $1 \mathrm{~cm}$ graduate ruler, and its basal diameter with a digital caliper $(0.01 \mathrm{~mm}$ resolution). The volume index (VI, Wilson-Kokes et al. 2013) was calculated as follows:

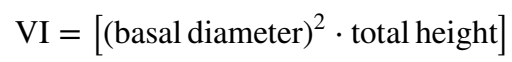

The relative growth rate in height (RGRh), the relative growth rate in basal diameter (RGRd) and the rate of production of new leaves (RGRnl) were determined according to Whitehead and Myerscough (1962). Before starting the treatments, the last expanded leaf was tagged with a color wire to separate the leaves expanded before and after the flooding. After the end of the experiment, leaves were scanned and the leaf area was determined with the software Image J (https://imagej.nih.gov/ij/). Chlorophyll content was measured on the tagged leaf with a Minolta 502 SPAD chlorophyll meter; the values were adjusted to a linear model, and the slope was taken as a measure of the leaf senescence rate (SR). A slope close to zero implies no chlorophyll degradation, while a higher slope indicates steeper chlorophyll degradation, hence a higher leaf senescence rate.

The stomatal conductance ( $\mathrm{gs}, \mathrm{mmol} \mathrm{H}_{2} \mathrm{O} \mathrm{m} \mathrm{m}^{-2} \mathrm{~s}^{-1}$ ) was determined with a porometer Decagon SC1, and the electron transport rate (ETR, $\mu \mathrm{mol}$ electrons $\mathrm{m}^{-2} \mathrm{~s}^{-1}$ ) with a modulated fluorescence meter (Hansatech FMSII, UK). Both variables were measured on the latest expanded leaf at the beginning and at the end of the experiment, 3 weeks later. The measurements were carried out between 10.30 and $13.00 \mathrm{~h}$, on cloudless days. The irradiance during the measurements ranged between 1300 and $1800 \mu \mathrm{mol}$ photons $\mathrm{m}^{-2} \mathrm{~s}^{-1}$.

At the end of the experiment, the total biomass and dry matter partitioning were determined after drying the material at $65{ }^{\circ} \mathrm{C}$ to constant weight. Specific leaf area (SLA) was determined from a pool of leaves expanded during the flooding period. Leaf nitrogen content $(\mathrm{N})$ was determined from the same pool of leaves used for specific leaf area, using the Kjeldahl method for total nitrogen (Brenmer 1996). 
The statistical analysis was carried out with $\mathrm{R} 3.2 .3$, using the package agricolae ( $\mathrm{R}$ Development Core Team 2017). The aov function was used for the ANOVA, with clone and treatment as factors, and the post hoc analysis was carried out with the LSD test. The Principal Components Analysis (PCA) was performed using the means of each clone and treatment, and the data were standardized and centered.

\section{Results}

The F50 treatment caused a more marked effect upon willow growth than F10, as summarized by the Principal Component Analysis (PCA, Fig. 1) and the ANOVA analysis (Table 2). The first component explained $41 \%$ of the observed variability, separating the Control and F10 treatments on one side, and the F50 on the other. Along this axis, all the growth-related variables decreased in the F50 treatment, while there was no difference between F10 and Control. The F50 treatment reduced final height and diameter (combined as volume index, VI), total dry weight (TDW), total leaf area (TLA) and number of leaves (NL). The relative growth rate in height (RGRh), the relative growth rate in basal diameter (RGRd) and the production of new leaves (RGRnl) were also reduced in F50. On the other hand, other variables along the first component were increased in F50, like the leaf abscission rate (AR), the specific leaf area (SLA) and the nitrogen content per unit leaf area (N).

The second principal component (Fig. 1) represented variables that differed at species level, since there were two defined groups: the $S$. alba (SA) and $S$. amygdaloides $(\mathrm{SAM})$ cluster on one side, and the $S$. matsudana $(\mathrm{SM})$ and $S$. matsudana $\times S$. nigra $(\mathrm{M} \times \mathrm{N})$ hybrids on the other. The $\mathrm{SM}$ and $\mathrm{M} \times \mathrm{N}$ clones had a higher root-to-shoot ratio (RSR), roots-to-leaves ratio (RLR), stomatal conductance (gs), and a slightly higher specific leaf area (SLA) than the SA and SAM clones. On the other hand, the

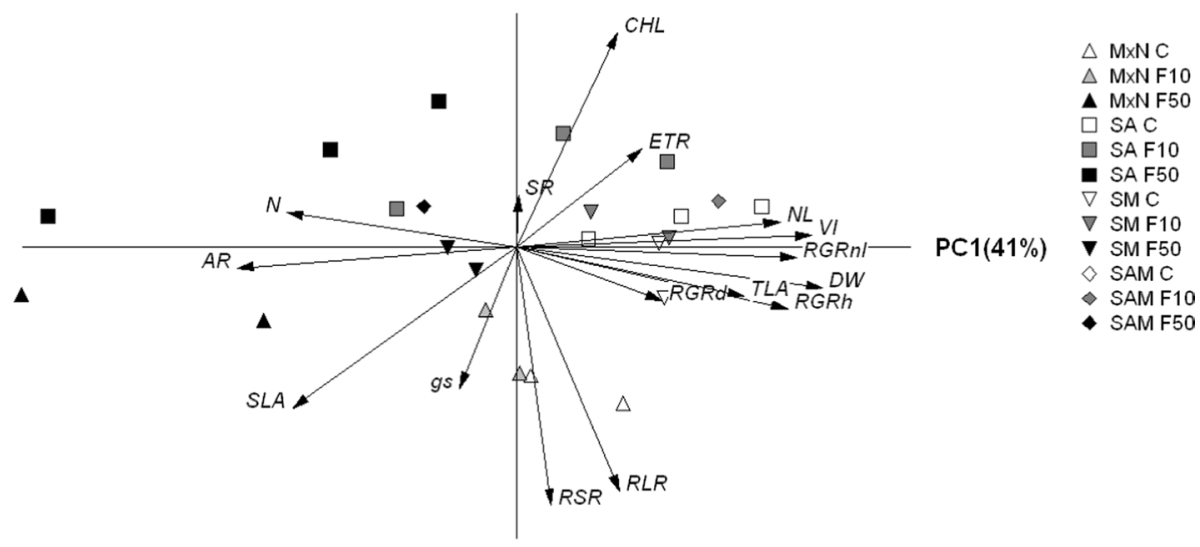

PCA $2(17 \%)$

Fig. 1 Principal component analysis (PCA) of plants grown from cuttings of eight willow clones analyzed under three treatments: Control (plants watered to field capacity); F10 (plants submerged $10 \mathrm{~cm}$ above soil level) and F50 (plants submerged $50 \mathrm{~cm}$ above soil level). $\mathrm{M} \times \mathrm{N}: S$. matsudana $\times S$. nigra hybrids; SA: Salix alba; SM: Salix matsudana; SAM: Salix amygdaloides. The symbols represent the average value of each genotype and treatment 
Table 2 ANOVA table including the full name and units of the variables measured in an experiment analyzing the responses of plants grown from cuttings of eight willow genotypes (clone factor) analyzed under three treatments: Control (plants watered to field capacity); F10 (plants submerged $10 \mathrm{~cm}$ above soil level) and F50 (plants submerged $50 \mathrm{~cm}$ above soil level) to different floodwater depth (treatment factor)

\begin{tabular}{|c|c|c|c|c|}
\hline Variable name & Abbreviation and units & Clone & Treatment & Interaction \\
\hline Relative growth rate in height & $\mathrm{RGRh}, \mathrm{cm}_{\text {day }}{ }^{-1}$ & 0.222 & $2 \times 10^{-16 * * *}$ & $4.73 \times 10^{-7 * * *}$ \\
\hline $\begin{array}{l}\text { Relative growth rate in } \\
\text { diameter }\end{array}$ & RGRd, mm day ${ }^{-1}$ & $0.006^{* *}$ & $2 \times 10^{-16 * * *}$ & $0.018^{*}$ \\
\hline New leaves production rate & RGRnl, leaves day ${ }^{-1}$ & $6 \times 10^{-6 * * *}$ & $1.4 \times 10^{-11 * * *}$ & $0.0004 * * *$ \\
\hline Final basal diameter & $\mathrm{D}, \mathrm{mm}$ & $2.7 \times 10^{-7 * * *}$ & $3.8 \times 10^{-14 * * *}$ & 0.428 \\
\hline Final height & $\mathrm{H}, \mathrm{cm}$ & $2 \times 10^{-6 * * *}$ & $4.7 \times 10^{-16} * * *$ & 0.216 \\
\hline Volume index & $\mathrm{VI}, \mathrm{cm}^{3}$ & $2 \times 10^{-8 * * *}$ & $4.7 \times 10^{-12 * * *}$ & 0.641 \\
\hline Total dry weight & TDW, g & $2 \times 10^{-12 * * *}$ & $2 \times 10^{-16 * * *}$ & 0.666 \\
\hline Root to shoot ratio & RSR & $2 \times 10^{-16 * * *}$ & $3 \times 10^{-9 * * *}$ & 0.137 \\
\hline Root to leaves ratio & RLR & $2 \times 10^{-16 * * *}$ & $2 \times 10^{-16 * * *}$ & $0.001 * *$ \\
\hline Chlorophyll content $^{\mathrm{a}}$ & CHL, SPAD units & $2 \times 10^{-16 * * *}$ & $0.0002 * * *$ & 0.070 \\
\hline Senescence rate & SR, SPAD day ${ }^{-1}$ & $1 \times 10^{-7 * * *}$ & $0.005^{* *}$ & 0.099 \\
\hline Nitrogen content ${ }^{\mathrm{b}}$ & $\mathrm{N}, \mu \mathrm{g} \mathrm{cm}^{-2}$ & $3.6 \times 10^{-15 * * *}$ & $8.7 \times 10^{-11 * * *}$ & 0.358 \\
\hline Total leaf area & TLA, $\mathrm{cm}^{2}$ & $2 \times 10^{-16 * * *}$ & $2.2 \times 10^{-7 * * *}$ & 0.876 \\
\hline Abscission rate & $\mathrm{AR}$, leaves day ${ }^{-1}$ & $0.0002 * * *$ & $1.7 \times 10^{-10 * * *}$ & $0.012 *$ \\
\hline Number of leaves & $\mathrm{NL}$ & $2 \times 10^{-16 * * *}$ & $10^{-13 * * *}$ & 0.769 \\
\hline Electron transport rate ${ }^{a}$ & ETR, $\mu \mathrm{mol} \mathrm{e} \mathrm{m}^{-2} \mathrm{~s}^{-1}$ & 0.119 & 0.623 & 0.254 \\
\hline Stomatal conductance ${ }^{\mathrm{a}}$ & $\mathrm{gs}, \mathrm{mmol} \mathrm{H}_{2} \mathrm{O} \mathrm{m}^{-2} \mathrm{~s}^{-1}$ & 0.749 & $0.0003 * * *$ & 0.584 \\
\hline Specific leaf area ${ }^{\mathrm{b}}$ & SLA, $\mathrm{g} \mathrm{cm}^{-2}$ & $1.5 \times 10^{-16 * * *}$ & $1.5 \times 10^{-9} * * *$ & 0.415 \\
\hline
\end{tabular}

The values indicated are the levels of significance. ${ }^{* * *} p<0.001 ; * * p<0.01 ; * p<0.05$

${ }^{a}$ Measured on the latest expanded leaf

${ }^{\mathrm{b}}$ Measured on the leaves expanded during flooding

SA and SAM genotypes had a higher chlorophyll content in the leaves expanded under flooding (CHL), a higher electron transport rate (ETR) and a faster leaf senescence rate of the basal leaves (SR).

After 1 week of flooding, hypertrophied lenticels and adventitious roots started to develop in the submerged parts of the cuttings and stems of both flooding treatments in all clones (data not shown).

The F50 treatment reduced the total dry biomass accumulation in a higher degree than F10 in all genotypes (Fig. 2), and the total leaf area as well (S.Fig. 1). The Root to Shoot Ratio (RSR) was reduced by both F10 and F50 treatments compared to Control plants in most clones. The exception were the flooded clones SA64 and MN22 that had a similar RSR to Control plants, and clone M692 which showed an increase in this ratio compared to controls.

Nitrogen content and Specific Leaf Area were both increased, albeit not always significantly, in the F50 treatment compared to the Control and F10 plants (Table 2 and Fig. 3). There were also genotypic differences: the $\mathrm{M} \times \mathrm{N}$ hybrids had a higher SLA and a lower $\mathrm{N}$ content than the other clones.

Stomatal conductance did not differ among the F10 treatments and the Control except in clone SA64 (Fig. 4a and Table 2). Plants from the F50 treatment had similar or higher 

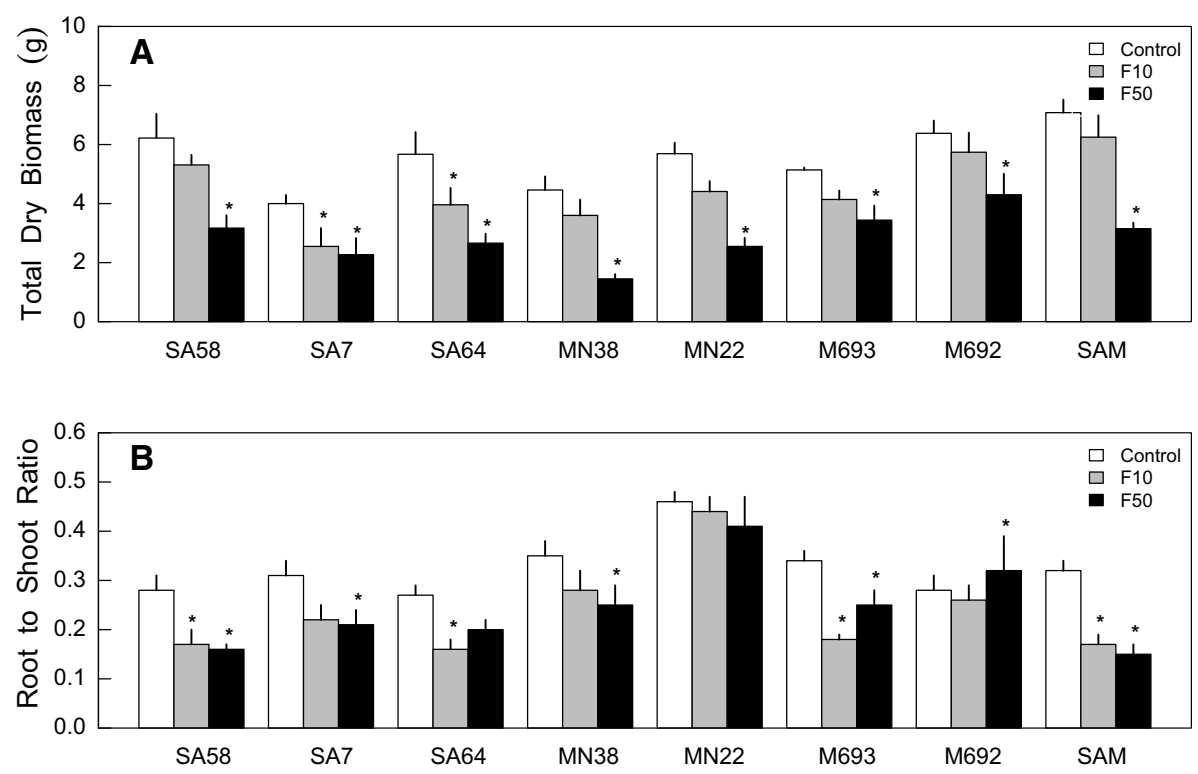

Fig. 2 Total Dry Biomass (a) and Root-to-Shoot Ratio (b) of plants grown from cuttings of eight willow clones analyzed under three treatments: Control (plants watered to field capacity); F10 (plants submerged $10 \mathrm{~cm}$ above soil level) and F50 (plants submerged $50 \mathrm{~cm}$ above soil level). Bars: standard error of the mean. Values with an asterisk indicate significant differences from the control treatment of the same genotype (5\% LSD). $\mathrm{N}=4$ or 5 (for each genotype and treatment)

values of gs than those of control plants, and the differences were statistically significant in clones SM692 and SM693.

Clone SA64 experienced a reduction in chlorophyll content in the F10 treatment, while there were no differences for the other clones (Fig. 4 b and Table 2). For F50, chlorophyll content decreased in clone SA7 and it increased in clone M693. There were no significant differences for either treatments or genotypes in ETR values (Table 2, data not shown).

In the F50 treatment, some plants were totally submerged while others were not. A correlation analysis was carried out to analyze the effects of the degree of submergence on growth. The absolute growth (final height minus initial height) was plotted against the degree of submergence (Fig. 5a). There was a strong correlation $(\mathrm{r}=0.94, p<0.001)$ between these variables, where the degree of submergence explained $88 \%$ of the variability of growth in height. In the completely submerged plants (negative values), the increment in height was close to zero. The results were similar for the correlations between relative growth rate in height, total biomass and total leaf area against the degree of submergence (Fig. 5b-d, respectively). Meanwhile, in case of partially submerged plants, the more the plant emerged above water, the higher the growth it showed. This is reflected in the stronger correlation between absolute growth and initial height for the F50 treatment, compared with F10 and Control (S. Fig. 2). 

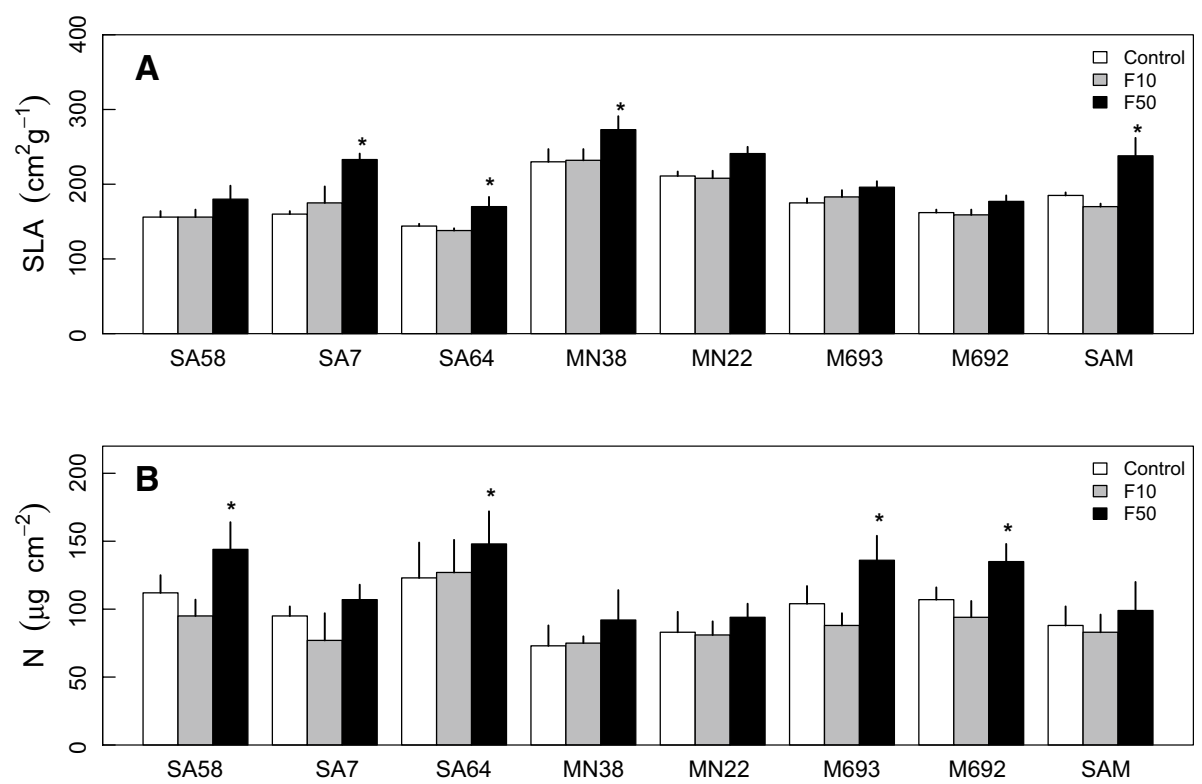

Fig. 3 Specific leaf area (SLA, a) and nitrogen content per unit leaf area (N, b) of plants grown from cuttings of eight willow clones analyzed under three treatments: Control (plants watered to field capacity); F10 (plants submerged $10 \mathrm{~cm}$ above soil level) and F50 (plants submerged $50 \mathrm{~cm}$ above soil level). Bars: standard error of the mean. Values with an asterisk indicate significant differences from the control treatment of the same genotype (5\% LSD). $\mathrm{N}=4$ or 5 (for each genotype and treatment)

\section{Discussion}

The tolerance to flooding is based on a set of strategies to overcome the energy and carbohydrate crisis that brings with it the restriction of access to $\mathrm{O}_{2}$ and $\mathrm{CO}_{2}$ (Kreuzwieser et al. 2004), the LOES and LOQS response patterns being the opposite extremes (Voesenek and Bailey-Serres 2015). Willow cuttings of all genotypes responded with growth arrest to complete submergence in our study. This growth arrest response is typical of the LOQS syndrome, and contributes to the saving of carbohydrates that are in short supply under hypoxia or anoxia (Voesenek and Bailey-Serres 2015). In spite of the differences in growth response, all clones developed hypertrophied lenticels and adventitious roots under the F50 treatment, as an avoidance strategy to facilitate the survival of the submerged organs.

The ability to perform underwater photosynthesis ameliorates sugar starvation during flooding (Colmer and Voesenek 2009). Underwater photosynthesis is limited by low irradiance and slow gas diffusion in water, and this can be alleviated by the occurrence of gas films in the submerged leaves (Colmer and Pedersen 2007). Besides the amount of light and the occurrence of leaf gas films, submerged plants need to develop leaves with a different morphology and anatomy to be able to carry out underwater gas exchange. One plastic response of completely submerged plants is the increase of the specific leaf area (SLA) with more elongated and thinner leaves (Mommer and Visser 2005). A high correlation between SLA and nitrogen use efficiency has been shown among species (Poorter and Evans 1998). In addition, species with high SLA have less nitrogen invested in pigment protein and more invested in Rubisco compared to low 

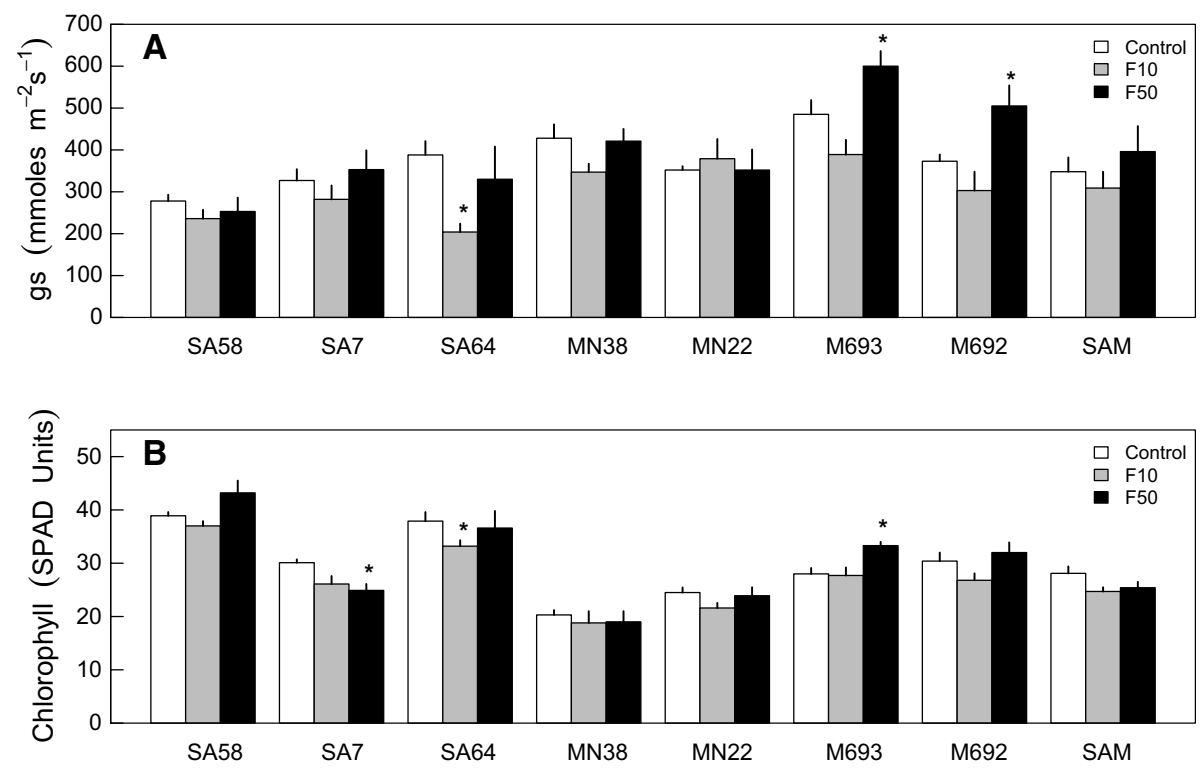

Fig. 4 Stomatal conductance (gs, a) and chlorophyll content of the latest expanded leaf (b) of plants grown from cuttings of eight willow clones analyzed under three treatments: Control (plants watered to field capacity); F10 (plants submerged $10 \mathrm{~cm}$ above soil level) and F50 (plants submerged $50 \mathrm{~cm}$ above soil level). Bars: standard error of the mean. Values with an asterisk indicate significant differences from the control treatment of this genotype ( $5 \%$ LSD). $\mathrm{N}=4$ or 5 (for each genotype and treatment)

SLA species (Poorter and Evans 1998). These traits may have an effect on the photosynthetic rate after the flooding episode ends, eliminating the restrictions on gas exchange. In poplar, a higher leaf nitrogen content increased net photosynthetic rate and leaf area (Cooke et al. 2005). Willows of most genotypes responded with significantly increased SLA and leaf nitrogen content to complete submergence. Immediately after the end of the flooding treatment, the stomatal conductance was similar or higher in F50 plants than in the Control treatment, and the ETR was not reduced by flooding.

All things considered, it seems that the photosynthetic machinery did not suffer from great damage during the flooding episode, since there was no reduction in chlorophyll content in most genotypes and the extra nitrogen could be destined to increase the Rubisco content. It has been proposed that Rubisco may serve as a storage protein, in addition to its catalytic functions (Warren et al. 2003). It is possible that a higher content of Rubisco might increase the photosynthetic rate during the post-flooding period, compensating for the growth reduction under flooding. Even without a higher photosynthetic rate, the increased Rubisco content could bring an advantage for willows in the post-flooding period, since $\mathrm{N}$ could be remobilized and used for the development of new leaves, thereby increasing growth. In Populus deltoides, it was found that the previously flooded plants had a higher growth rate than the non-flooded plants in the post-stress period (Rodriguez et al. 2015). The higher growth rate was caused by an increase in leaf area and not by a higher photosynthetic rate (Rodriguez et al. 2015). It has been proposed that an increased nitrogen content per leaf area is an acclimation to drought in willows (Weih et al. 2011), and it seems that something similar happens under deep 

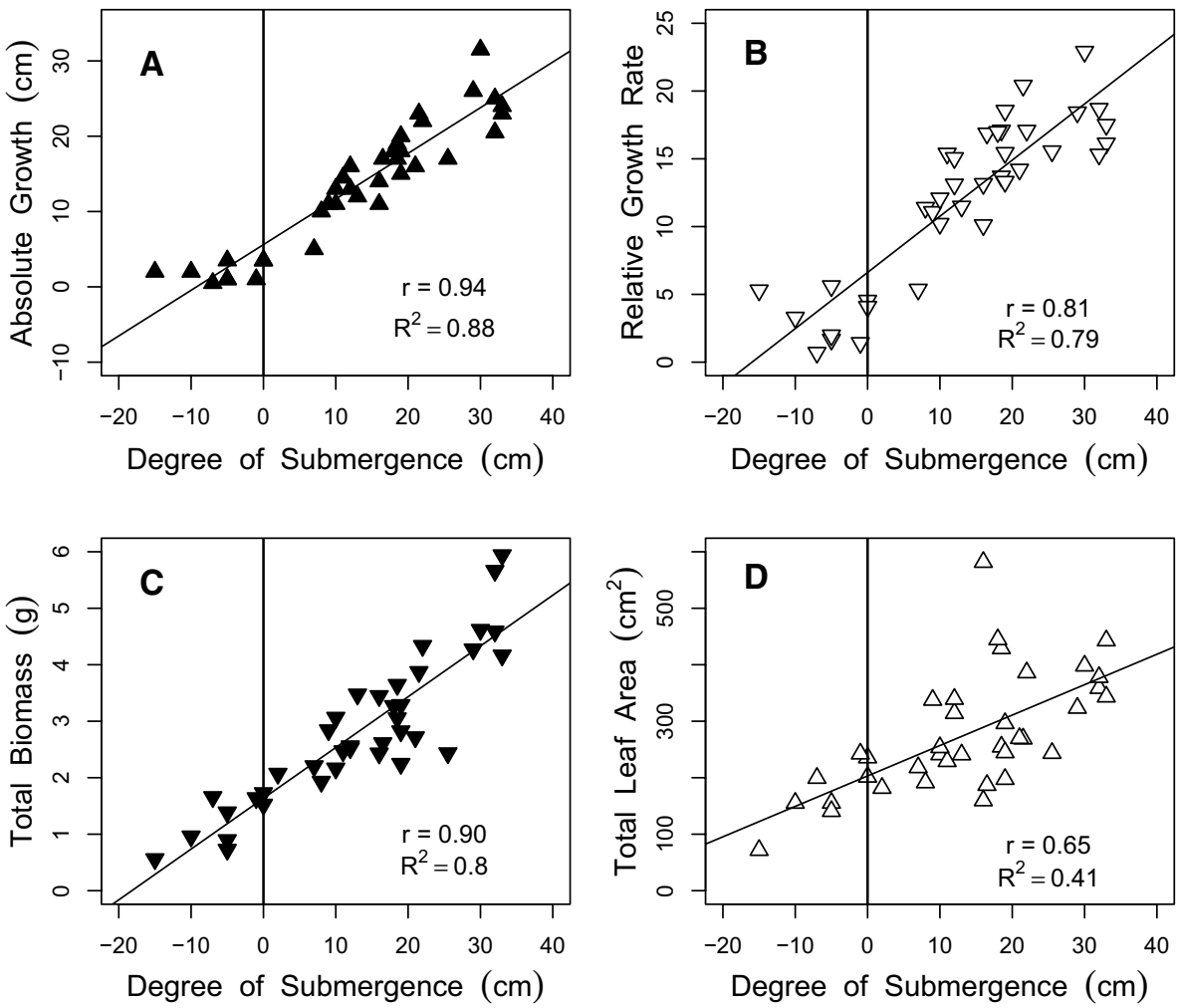

Fig. 5 Correlation analysis between growth and submergence in the F50 treatment, for plants grown from cuttings of eight willow clones. The degree of submergence was measured as the distance between the apical meristem of the plant and the water surface, which represents the zero level. The vertical bars divide the submerged plants (negative values) from the ones that emerged from the water surface (positive values). Absolute growth: final minus initial height. The relative growth rate applies to the growth in height, multiplied by $10^{-3}$. r: Pearson correlation coefficient; $R^{2}$ is the adjusted $\mathrm{R}$ square value. $\mathrm{N}=38$

flooding. In poplar plants under partial flooding, nitrogen uptake was not significantly reduced, but it was absorbed mainly as ammonium instead of nitrate (Kreuzwieser et al. 2004). It is possible to speculate than in willows, flooded plants had a similar nitrogen absorption rate than controls, and the increased content is due to the reduction in leaf area.

\section{Conclusion and management implications}

Our initial hypothesis on willow cuttings acclimation to flooding was corroborated for the eight studied genotypes, since flooding changed plant and leaf traits in different ways for the various clones according to the depth of the floodwater. These results are similar to those previously described for $S$. alba, showing a growth decrease along with the depth of the flooding (Markus-Michalczyk et al. 2016). The complete submergence reduced growth in a higher degree and caused more changes at morphological and physiological level than partly submergence of the belowground biomass. These results are similar to the reported 
for Alnus incana (Iwanaga and Yamamoto 2008), where plants submerged $1 \mathrm{~cm}$ above soil level experienced less reduction in photosynthesis, stomatal conductance and biomass accumulation than plants submerged $30 \mathrm{~cm}$ above soil level.

These changes not only may affect the survival under deep and prolonged floods, but also may have lasting effects on photosynthesis and growth recovery in the post-flooding period. Clones which maintain higher root biomass and nitrogen leaf content will probably have a faster recovery, once the flooding passes.

The degree of submergence was determined mainly by the height of the plant at the beginning of the experiment $(\mathrm{r}=0.88)$. Although there was no mortality during the experiment, clones that were completely submerged since the beginning were unable to avoid total submergence by the rapid extension of their stems. For the forestation of lowland areas with high risk of flooding during the early stages of establishment, it will be better to use willow clones with an early sprouting date and fast initial growth. For young plants, this will reduce the risk of being completely covered by floodwater and consequently diminish the negative impact of submergence on the early growth. This faster initial growth can also be achieved by using bigger cuttings for plantations in areas that may experience flooding episodes. Longer cuttings increase early growth and survival of willow plantations (Rossi 1999) likely because of higher carbohydrate content and a more favorable hormonal balance for adventitious root development (Zhao et al. 2014).

Acknowledgements Thanks to M. Bartolozzi, S. Martínez Alonso and J. Vera Bahima for the technical assistance. VMCL is a researcher from CONICET. MER and GND held fellowships from CONICET.

Funding This work was funded by Ministry of Agro Industry, Argentina, to VMCL (PIA 12012).

\section{Compliance with ethical standards}

Conflict of interest The authors declare that they have no conflicts of interest.

\section{References}

Balatinecz J, Mertens P, De Boever L, Yukun H, Jin J, van Acker J (2014) Properties, processing and utilization. In: Isebrands J, Richardson J (eds) Poplars and willows. Trees for society and the environment, FAO, Rome and CAB International, pp 258-261. http://www.fao.org/forestry/ipc/69946@158687/en/. Accessed 31 Aug 2017

Blom CWPM (1999) Adaptations to flooding stress: From plant community to molecule. Plant Biol $1: 261-273$

Brenmer JM (1996) Nitrogen total. In: Sparks DL (ed) Methods of soil analysis part 3: chemical methods. SSSA Book Series 5. Soil Science Society of America, Madison, WI, pp 1085-1122

Cerrillo T, Rodríguez ME, Achinelli F, Doffo G, Luquez VMC (2013) Do greenhouse experiments predict willow responses to long-term flooding events in the field? Bosque 34:71-79. https://doi.org/10.4067/ S0717-92002013000100009

Cerrillo T, Grande J, Monteoliva S, Luquez V, García A, Braccini C, Fernández P, Thomas E, Amico I, Fosco I, Achinelli F, Casaubón E, Villaverde R (2016) Advances in a willow (Salix spp.) breeding program in Argentina for different wood applications. In: Abstracts of submitted papers to the 25th session of the International Poplar Commission, FAO and German Federal Ministry of Food and Agriculture, Berlin, Germany, 13-16 September 2016. http://www.fao.org/forestry/45092-0fcd1e7430938785c3e2 c0a0a03329a88.pdf. Accessed 26 Sept 2017

Colmer T, Pedersen O (2007) Underwater photosynthesis and respiration in leaves of submerged wetland plants: gas films improve $\mathrm{CO}_{2}$ and $\mathrm{O}_{2}$ exchange. New Phytol 177:918-926. https://doi.org/10.1111 /j.1469-8137.2007.02318.x 
Colmer T, Voesenek LACJ (2009) Flooding tolerance: suites of plants traits in variable environments. Funct Plant Biol 36:665-681. https://doi.org/10.1071/FP09144

Cooke JEK, Martin TA, Davis JM (2005) Short term physiological and developmental response to nitrogen availability in hybrid poplar. New Phytol 167:41-62. https://doi.org/10.1111/j.1469-8137.2005 .01435.x

Dickmann D, Kuzovkina J (2014) Poplars and willows of the world, with emphasis on silviculturally important species. In: Isebrands J, Richardson J (eds) Poplars and willows. Trees for society and the environment, FAO, Rome and CAB International, pp 8-83. http://www.fao.org/forestry/ipc/6994 6@158687/en/. Accessed 31 Aug 2017

Doffo G, Monteoliva S, Rodríguez ME, Luquez VMC (2017) Physiological responses to alternative flooding and drought stress episodes in two willows (Salix spp.) clones. Can J Forest Res 47:174182. https://doi.org/10.1139/cjfr-2016-0202

Garssen A, Baatrup-Pedersen A, Voesenek LACJ, Verhoeven JTA, Soons M (2015) Riparian plant community responses to increased flooding: a meta-analysis. Glob Change Biol 21:2881-2890. https:// doi.org/10.1111/gcb.12921

Iwanaga F, Yamamoto F (2008) Effects of flooding depth on growth, morphology and photosynthesis in Alnus japonica species. New For 35:1-14. https://doi.org/10.1007/s11056-007-9057-4

Karrenberg S, Edwards PJ, Kollmann J (2002) The life history of Salicaceae living in the active zone of floodplains. Freshw Biol 47:733-748

Kreuzwieser J, Rennenberg H (2014) Molecular and physiological responses of trees to waterlogging stress. Plant Cell Environ 37:2245-2259. https://doi.org/10.1111/pce.12310

Kreuzwieser J, Papadopoulou E, Rennenberg H (2004) Interaction of flooding with carbon metabolism of forest trees. Plant Biol 6:299-306. https://doi.org/10.1055/s-2004-817882

Li S, Martin LT, Reza Pezeshki M, Douglas Shields F Jr. (2005) Responses of black willow (Salix nigra) cuttings to simulated herbivory and flooding. Acta Oecol 28:173-180. https://doi.org/10.1016 /j.actao.2005.03.009

Ma Q, Lebedys A (2014) Markets, trends and outlook. In: Isebrands J, Richardson J (eds) Poplars and willows. Trees for society and the environment, FAO, Rome and CAB International, pp 562-574. http://www.fao.org/forestry/ipc/69946@158687/en/. Accessed 31 Aug 2017

Markus-Michalczyk H, Hanelt D, Jensen K (2016) Effects of tidal flooding on juvenile willows. Estuaries Coasts 39:397-405. https://doi.org/10.1007/s12237-015-0014-8

Mommer L, Visser EJW (2005) Underwater photosynthesis in flooded terrestrial plants: a matter of leaf plasticity. Ann Bot 96:581-589. https://doi.org/10.1093/aob/mci212

Poorter H, Evans JR (1998) Photosynthetic nitrogen-use efficiency of species that differ inherently in specific leaf area. Oecologia 116:26-37

R Core Team (2017) R: a language and environment for statistical computing. R Foundation for Statistical Computing, Vienna, Austria. ISBN 3-900051-07-0. http://www.R-project.org. Accessed 25 May 2017

Rodriguez ME, Achinelli F, Luquez VMC (2015) Leaf traits related to productivity in Populus deltoides during the post-flooding period. Trees 29:953-960. https://doi.org/10.1007/s00468-015-1189-0

Rossi P (1999) Length of cuttings in establishment and production of short rotation plantations of Salix "Aquatica". New For 18:161-177

Stanturf J, Van Oosten C (2014) Operational poplar and willow culture. In: Isebrands J, Richardson J (eds) Poplars and willows. Trees for society and the environment, FAO, Rome and CAB International, pp 200-247. http://www.fao.org/forestry/ipc/69946@158687/en/. Accessed 31 Aug 2017

Van Splunder I, Coops H, Voesenek LACJ, Blom CWPM (1995) Establishment of alluvial forest species in floodplains: the role of dispersal timing, germination characteristics and water level fluctuations. Acta Bot Neerl 44:269-275

Voesenek LACJ, Bailey-Serres J (2015) Flood adaptive traits and process: an overview. New Phytol 206:57-73. https://doi.org/10.1111/nph.13209

Volk TA, Ballard B, Robison DJ, Abrahamson LP (2004) Effect of cutting storage conditions during planting operations on the survival and biomass production of four willows (Salix L.) clones. New For 28:63-78

Wang C, Xie Y, He Y, Li X, Yang W, Li C (2017) Growth and physiological adaptation of Salix matsudana Koidz to periodic submergence in the hydro-fluctuation zone of the Three Gorges Dam Reservoir of China. Forest 8:283. https://doi.org/10.3390/f8080283

Warren CR, Dreyer E, Adams MA (2003) Photosynthesis-Rubisco relationships in foliage of Pinus sylvestris in response to nitrogen supply and the proposed role of Rubisco and amino acids as nitrogen stores. Trees 17:359-366 
Weih M, Bonosi L, Ghelardini L, Rönnberg-Wästljung AC (2011) Optimizing nitrogen economy under drought: increased leaf nitrogen is an acclimation to water stress in willow (Salix spp.). Ann Bot 108:1347-1353. https://doi.org/10.1093/aob/mcr227

Whitehead FH, Myerscough PJ (1962) Growth analysis of plants. New Phytol 61:314-321

Wilson-Kokes L, Emerson P, DeLong C, Thomas C, Skousan J (2013) Hardwood tree growth after eight years on brown and gray mine soils in West Virginia. J Environ Qual 42:1353-1362. https://doi. org/10.2134/jeq2013.04.0113

Zhao X, Zheng H, Li S, Yang C, Jiang J, Liu G (2014) The rooting of poplar cuttings: a review. New For 45:21-34. https://doi.org/10.1007/s11056-013-9389-1 